\title{
DESCRIÇÃO, PRODUTIVIDADE E ESTABILIDADE DA CULTIVAR DE SOJA IAC-24, RESISTENTE A INSETOS ${ }^{(1)}$
}

\author{
MANOEL ALBINO COELHO DE MIRANDA ${ }^{(2)}$;NELSON RAIMUNDO BRAGA ${ }^{(2)}$; \\ ANDRÉ LUIZ LOURENÇÃO ${ }^{(2,4)}$;FERNANDO TOLEDO SANTOS DE MIRANDA ${ }^{(3)}$; \\ SANDRA HELENA UNÊDA ${ }^{(3)}$; MARGARIDA FUMIKO ITO(2)
}

\begin{abstract}
RESUMO
A cultivar de soja IAC-24 foi obtida pelo método genealógico modificado, a partir do cruzamento IAC80-1177 x IAC 83-288, tendo sido avaliada com a designação IAC93-3335, em 14 ambientes nos Estados de São Paulo e de Minas Gerais. Os ensaios finais foram conduzidos em Conceição das Alagoas (MG), Campinas (SP); Mococa (SP), em 1994/95; em Conceição das Alagoas, Campinas, Tarumã (SP) em Votuporanga (SP), em 1995/96; em Conceição das Alagoas, Campinas, Tarumã, Votuporanga, Mococa, Capão Bonito (SP) e Ribeirão Preto (SP) em 1996/97. Os experimentos foram instalados no delineamento de blocos ao acaso com quatro repetições. O menor rendimento de grãos ocorreu em Campinas com 2.302 kg.ha ${ }^{-1}$ e o maior em Conceição das Alagoas com 4.003 kg.ha ${ }^{-1}$, em 1996/97. Na análise conjunta os efeitos de genótipos, ambientes e sua interação foram significativos. O genótipo IAC-24 apresentou rendimento de grãos superior, com $3.480 \mathrm{~kg} \cdot \mathrm{ha}^{-1}$, superando significativamente o controle IAC-15. A cultivar IAC24 apresenta índices de resistência a insetos próximos aos da cultivar IAC-100, além de resistência à pústula bacteriana (Xanthomonas campestris pv. glycines), ao fogo sevalgem (Pseudomonas seringae pv. Tabaci), ao cancro-da-haste (Diaporthe phaseolorum f.sp. meridionalis) e à mancha-café (soybean mosaic virus, SMV). Em semeaduras de novembro, esse cultivar semiprecoce, com período juvenil longo, floresceu aos 57 dias após a semeadura, com estatura de $72 \mathrm{~cm}$ no fim do ciclo. A duração do período entre a emergência das plântulas e o estádio de maturação das plantas (R-8) foi de 124 dias, dentro do grupo de maturação semiprecoce. O rendimento médio de grãos nos 14 ambientes foi de $3.480 \mathrm{~kg} \cdot \mathrm{ha}^{-1}$. As suas plantas apresentam pubescência marrom, flor branca e sementes amarelas com hilo marrom e mostra resistência a insetos mastigadores e sugadores, semelhante à da cultivar IAC-100. O desempenho apresentado pela cultivar IAC-24 sugere sua indicação para condições edafoclimáticas similares às do Estado de São Paulo.
\end{abstract}

Palavras-chave: Glycine max, resistência a insetos.

(1) Recebido para publicação em 16 de fevereiro de 2001 e aceito em 13 de novembro de 2002.

$\left(^{2}\right)$ Instituto Agronômico (IAC), Caixa Postal 28, 13001-970, Campinas(SP).

${ }^{3}$ ) Doutorando da Escola Superior de agricultura "Luiz de Queiroz", Caixa Postal 9, Piracicaba (SP).

$\left({ }^{4}\right)$ Com bolsa de produtividade de pesquisa do CNPq. 


\title{
ABSTRACT \\ DESCRIPTION, YIELD AND STABILITY OF EARLY SOYBEAN INSECT RESISTANT CULTIVAR IAC-24
}

\begin{abstract}
The breeding line IAC 93-3335 (IAC-24) was selected from the cross IAC 80-1177 x IAC 83-288 through single seed descent method (SSD) by the IAC breeding program to increase insect resistance. This cultivar has in its background two important genotypes: PI 229358 e PI 227687 (USDA germplasm), as sources of resistance to insect. The cultivar was evaluated at experimental fields in Conceição das Alagoas (MG), Campinas (SP) and Mococa (SP) (1994/95), in Conceição das Alagoas, Campinas, Tarumã (SP) and Votuporanga (SP) (1995/96) and Conceição das Alagoas, Campinas, Tarumã, Votuporanga, Mococa, Capão Bonito (SP) and Ribeirão Preto (SP) (1996/97). The trials were installed using randomized block design, with four replications. Results of productivity indicate that the cultivar IAC-24 shows lower yields at Campinas, with $2302 \mathrm{~kg} \cdot \mathrm{ha}^{-1}$, and higher yields at Conceição das Alagoas, with $4003 \mathrm{~kg} \cdot \mathrm{ha}^{-1}$. The IAC24 soybean exhibits long juvenile period, flowering time at 57 days, and complete life cicle around 124 days after seed germination. Plants show brown pubescence, yellow seeds with brown hilum. The new cultivar is resistant to bacterial pustule (Xanthomonas campestris pv. glycines), "wildfire" (Pseudomonas seringae pv tabaci), stem cancker (Diaporthe phaseolorum f.sp. meridionalis) and soybean mosaic virus(SMV). Joint analysis showed significant effects of genotypes, environments and interactions. For each environment, joint analysis were also realized. The IAC-24 cultivar showed the highest yield (3.480 $\left.\mathrm{kg} . \mathrm{ha}^{-1}\right)$. The Dunnet test indicated that the difference was significant when compared with IAC-15. Among the lines, IAC-24 showed the lowest defoliation by caterpillars, and presented low pod damage similar to IAC-100 soybean cultivar. So, the new cultivar is resistant to insect damage, has good yield, and should be recommended for cultivation in State of São Paulo and similar environments.
\end{abstract}

Key words: Glycine max, insect resistance.

\section{INTRODUÇÃO}

O desenvolvimento de cultivares de soja mais resistentes a insetos, como IAC-17, IAC-18 e IAC-19, de ciclos de maturação distintos, proporcionou aos agricultores maior eficiência no controle integrado de pragas, na racionalização do uso da terra, da mãode-obra e dos equipamentos. A combinação ótima de cultivares pode reduzir a probabilidade de danos climáticos em fases críticas (semeadura, granação e maturação) da cultura. No entanto, a cultivar semiprecoce IAC-18 ainda apresenta vulnerabilidade à ação dos percevejos, causando a retenção foliar prejudicial à colheita mecânica.

Estudos realizados no IAC apontaram os genótipos PI 274453, PI 274454, IAC73-228, IAC782318, IAC80-596-2 e IAC80-4228 como resistentes aos percevejos pentatomídeos (Nezara viridula, Piezodorus guildinii e Euschistus heros (Rossetto et al, 1986; LOURENÇÃo et al., 1987).

A linhagem norte-americana D72-9601-1, selecionada para resistência a Pseudoplusia includens, mostrou-se resistente à Anticarsia gemmatalis nas condições do Estado de São Paulo (REZENDE et al., 1980). Em dois anos de estudo em campo, a linhagem IAC782318 foi apenas levemente injuriada pela "broca dos ponteiros" (Epinotia aporema) (LoURENÇão e MiRANDA, 1983).
As PI 274453 e PI 274454, e a IAC78-228 mostraram danos irrisórios em áreas com altas populações de lagarta enroladeira, Omiodes indicata, que causou severos danos nos demais genótipos (LOURENÇão et al., 1985). A PI 227687 mostrou resistência aos coleópteros Diabrotica speciosa e Colaspis sp. em comparação a cultivares comerciais (REZENDE et al., 1980). Em relação à "mosca branca" (Bemisia tabaci), as PI 171451 e PI 229358 mostraram resitência do tipo "não-preferência" para oviposição (LOURENÇão e YUKI, 1982); a colonização deste inseto também foi reduzida nessas duas introduções, bem como na linhagem IAC78-2318 (LOURENÇÃo e MirANDA, 1987).

Recentemente, constatou-se que IAC-17 e IAC19 apresentam resistência do tipo "não-preferência" para oviposição, além de baixas colonização e atratividade para adultos de Bemisia tabaci biótipo B (VALLE e LouRENÇão, 2002). Os genótipos PI 227687, IAC73-228, IAC80-1177, IAC80-1191, IAC84-20-1 mostraram resistência em campo à queima-do-broto (brazilian bud blight), virose transmitida por espécies de "tripes" (Frankliniella sp.); tais acessos mostraramse, no entanto, suscetíveis quando infectados mecanicamente (LoURENÇão et al., 1989).

Os genótipos mencionados com diferentes graus de resistência a diversas espécies de insetos, introduzidos ou desenvolvidos pelo IAC, permitem o direcionamento do programa institucional 
de melhoramento genético de soja na busca de cultivares resistentes às principais pragas desta cultura. A seleção em campo é possível devido à alta freqüência de incidência de coleópteros crisomelídeos, principalmente Colaspis sp., e também ao fato de o mecanismo de resistência não ser exclusivo de uma determinada espécie de inseto (LAMBERT e KILEN, 1984).

A incorporação de características de resistência às doenças como pústula-bacteriana, fogo -selvagem, cancro-da-haste, bem como maior tolerância aos nematóides de galha (Meloidogyne sp.) e ao vírus do mosaico-comum, associada à maior resistência a insetos da cultura, nas cultivares de soja geradas no IAC contribuem para maior estabilidade produtiva da nova cultivar criada, como é o caso da IAC-24, objeto deste trabalho.

\section{MATERIAL E MÉTODOS}

As linhagens testadas nos experimentos finais foram obtidas mediante cruzamentos manuais e biparentais, cuja geneaologia e outras características encontram-se no quadro 1. A etapa preliminar envol- vendo avaliação visual de plantas e progênies foi desenvolvida no Centro Experimental de Campinas, do Instituto Agronômico.

Nas gerações $F_{4}$ e $F_{5}$, as melhores linhagens selecionadas, por ciclo, foram reunidas em experimentos preliminares, na forma de "látice simples" $(6 \times 6)$, com duas repetições por tratamento, para avaliação de produtividade. Neste caso, para maior controle local, os sub-blocos foram dispostos no sentido das operações de aração, gradagem e adubação.

Os ensaios preliminares foram instalados em Campinas, Tarumã, Ribeirão Preto e Conceição das Alagoas. As parcelas consistiram de três linhas de $4,0 \mathrm{~m}$, espaçadas em $0,5 \mathrm{~m}$. Na colheita de grãos, apenas a linha central foi utilizada, eliminando-se $0,5 \mathrm{~m}$ em cada extremidade.

$\mathrm{Na}$ etapa final, as linhagens superiores foram avaliadas quanto à produtividade, em blocos ao acaso, quatro repetições por tratamento. As duas linhas centrais de $5,0 \mathrm{~m}$ de comprimento foram utilizadas como área útil, eliminando-se 0,5 de cada extremidade, determinando-se o rendimento de grãos em $4,0 \mathrm{~m}^{2}$.

Quadro 1. Genealogia, rendimento de grãos, índice relativo ao padrão IAC-15, estatura das plantas, duração dos períodos emergência-florescimento (EF) e emergência-maturação (EM), em 14 experimentos de soja desenvolvidos em Campinas, Mococa, Tarumã, Ribeirão Preto, Votuporanga, Capão Bonito e Conceição das Alagoas, em 1994/95, 1995/ $96,1996 / 97$

\begin{tabular}{|c|c|c|c|c|c|c|}
\hline Genótipo & Genealogia & $\begin{array}{l}\text { Rendimento } \\
\text { de grãos }\end{array}$ & I.R. & $\begin{array}{c}\text { Estatura } \\
\text { das plantas }\end{array}$ & $\mathrm{EF}$ & EM \\
\hline & & kg.ha- ${ }^{-1}$ & & $\mathrm{~cm}$ & \multicolumn{2}{|c|}{ dias } \\
\hline IAC-24 & IAC80-1177 x IAC83-288 & $3.480^{(1)}$ & $(114)$ & 72 & 57 & 124 \\
\hline IAC93-1689 & BR-5 x FT-10 & 3.199 & $(104)$ & 74 & 52 & 123 \\
\hline IAC-18 & D72-9601-1 x IAC73-5115 & 3.190 & $(104)$ & 77 & 54 & 120 \\
\hline IAC93-1804 & IAC80-3354 x IAC82-3099 & 3.172 & $(104)$ & 70 & 50 & 120 \\
\hline IAC93-1556 & FT10 x IAC79-440 & 3.154 & $(103)$ & 80 & 55 & 125 \\
\hline IAC96-1672 & BR-5 x FT-10 & 3.103 & $(101)$ & 69 & 51 & 120 \\
\hline IAC93-1413 & IAC72 - 1174 x IAC79-440 & 3.089 & $(101)$ & 69 & 51 & 121 \\
\hline IAC-15 & IAC77-3086 x Paraná & 3.062 & $(100)$ & 82 & 53 & 121 \\
\hline IAC93-1436 & IAC82-1174 x FT-10 & 3.003 & $(98)$ & 72 & 52 & 122 \\
\hline IAC93-1704 & BR-5 x FT-10 & 2.988 & $(98)$ & 71 & 54 & 122 \\
\hline IAC 93-1568 & FT-10 x IAC79-440 & 2.968 & $(97)$ & 74 & 53 & 121 \\
\hline IAC93-1791 & IAC80-3354 x IAC82-3099 & 2.954 & $(96)$ & 70 & 52 & 123 \\
\hline Média & & 3.113 & & 73 & 53 & 122 \\
\hline $\mathrm{CV}(\%)$ & & 14,93 & & & & \\
\hline DMS 5\% & & 206 & & & & \\
\hline
\end{tabular}

$\left({ }^{1}\right)$ - Difere para mais do padrão IAC-15 ao nível de $5 \%$. 
Para a medição da magnitude da interação genótipo $x$ ambiente $(\mathrm{G} \times \mathrm{A})$, realizou-se a análise conjunta envolvendo anos e locais e anos dentro de locais. Os valores médios foram comparados com o da cultivar-padrão, utilizando-se do teste DUNNET unilateral a $5 \%$.

Mediu-se a estabilidade dos genótipos pela ecovalência (WRICKE e WEBER, 1986). A significância dos desvios dos quadrados médios da ecovalência foi calculada como proposto por Kang e Miller (1984) para avaliar a estabilidade de clones de cana-de-açúcar, e aplicado por MiRANDA (1999) em soja.

A ecovalência é um método de fácil utilização que permite comparar a estabilidade dos genótipos, no sentido agronômico, através dos desvios em relação a um genótipo ideal. Esse genótipo ideal apresentaria, segundo método de EBEHART e RUSSEL (1966), um coeficiente angular (b) em relação ao índice ambiental com valor 1 (genótipo responsivo). A ecovalência também pode ser entendida como uma decomposição da soma dos quadrados da interação G x A para cada genótipo, expressa em porcentagem (MirAnda, 1999).

Para facilitar as decisões de recomendação da nova cultivar, foi idealizado um sistema que leva em consideração a média do genótipo nas diferentes localidades e os desvios da regressão em relação a um genótipo ideal (responsivo), sendo valorizados aqueles que sejam superiores ao padrão referencial e apresentem desvios não significativos. As avaliações de resistência a insetos foram realizadas preliminarmente na etapa de obtenção de linhagens, quando foram atribuídas notas de desfolhamento às progênies.

Em fase posterior, experimentos específicos e conclusivos foram desenvolvidos para conferir o grau de resistência dos genótipos superiores a insetos, pragas importantes de soja (LourENÇão, 2000). Durante a fase de obtenção de semente genética, a cultivar foi infectada no estádio V-4 e avaliada no estádio R-6 (FeHr e CAVIness, 1977), com Diaporthe phaseolorum f.sp. meridionalis, agente do cancro-da-haste" pelo método do palito-de-dente (YORINORI, 1994), para confirmar observações de campo.

\section{RESULTADOS E DISCUSSÃO}

A cultivar IAC-24 resultou do cruzamento IAC80-1170 x IAC83-288, tendo sido avaliada sob a denominação de IAC 93-3335. A linhagem progenitora IAC80-1177 originou-se de D72-9601-1 x $\mathrm{F}_{1}$ (Davis $\mathrm{x}$ PI 227687) destacando-se primeiramente pela resistência em campo a percevejos pentatomídeos e posteriormente à virose queima-do-broto" (brazilian bud blight). A linhagem IAC 83-288, outra progenitora, é irmã de IAC-17 (D72-9601-1 x IAC-8), tendo sido avaliada para resistência a insetos em inúmeros ensaios anteriores.

Apesar de apresentar estatura das plantas inferior à da cultivar AC-18, a cultivar IAC-24 é igualmente suscetível ao acamamento, em determinadas situações que envolvam alta densidade populacional, época de semeadura favorável ao crescimento vegetativo e alta fertilidade do solo.

A duração do ciclo de maturação é próxima à da cultivar IAC-18, sendo ligeiramente mais longa que a da cultivar IAC-15. O rendimento de grãos de $3.480 \mathrm{~kg} \cdot \mathrm{ha}^{-1}$ superou em $14 \%$ o da cultivar IAC-15 (Quadro 1). Na análise conjunta constatou-se significância para os efeitos de genótipos, locais e interação (Quadro 2).

O desempenho de IAC-24 e demais genótipos foi avaliado em cada um dos locais (Quadro 3). O rendimento de grãos da cultivar IAC-24 em Campinas, envolvendo os valores dos anos 1994/95, 1995/96 e 1996/97, diferiu significativamente do obtido pela cultivar IAC-15 que apresenta suscetibilidade ao Diaporthe phaseolorum f.sp. meridionalis, presente na área do experimento.

Em Conceição das Alagoas e em Votuporanga, os rendimentos de grãos de IAC-24 foram semelhantes à cultivar referencial. Por outro lado, em Tarumã, o desempenho de IAC-24 foi bastante inferior, provavelmente devido ao acamamento verificado nas condições predominantes, ou seja, época de semeadura favorável ao crescimento vegetativo, alta densidade populacional (acima de 350.000 plantas por hectare) e alta fertilidade do solo. Em Mococa, Capão Bonito e Ribeirão Preto, houve tendência de IAC-24 apresentar rendimentos superiores aos da cultivar-padrão.

Os resultados de Capão Bonito foram considerados, apesar do coeficiente de variação apresentado, em face da ocorrência de alta infestação de insetos e pela provável presença de queima-do-broto.

Essa virose tem sido bastante freqüente nessa localidade, mostrando o comportamento superior da cultivar IAC-24. Outro trabalho já havia evidenciado a superioridade desta cultivar, em relação às cultivares IAC-15 e IAC-18, quanto à resistência a insetos mastigadores, equiparando-se à 'IAC-100'.

O mesmo ocorreu em relação ao grau de retenção foliar e ao índice de danos em sementes causados por percevejos. Quanto ao rendimento de grãos, na presença de pentatomídeos, com os dados convertidos a kg.ha- ${ }^{-1}$, a cultivar IAC-24 superou em $14 \%$ o da IAC-100, sendo inferior ao da IAC-18 em apenas $6 \%$. 
As análises conjuntas dentro de locais mostraram que a interação $G \times$ A não foi significativa nas localidades de Campinas e Tarumã, sugerindo a possibilidade de recomendação para determinado local (Quadro 4).

Em Tarumã, a cultivar IAC-24 apresentou alto índice de acamamento ao rendimento de grãos. Nesse caso, técnicas de manejo devem ser cogitadas para minimizar a propensão ao acamamento demonstrada pelo cultivar.

Pelos critérios de seleção adotados, a cultivar IAC-24 não seria eleita, pois, pelo conceito de ecovalência, interage com o ambiente de maneira não previsível, sendo responsável por $16,4 \%$ do total da soma de quadrados da interação $\mathrm{G} \times \mathrm{A}$, ao contrário da cultivar IAC-18 (Quadro 5). Essa observação já havia sido destacada por LOURENÇÃO et al . (2000).
No entanto, a cultivar IAC-24 mostrou rendimentos de grãos superiores, mesmo em ambientes desfavoráveis como nos três experimentos de Campinas, devido ao cancro-da-haste e no de Capão Bonito com a presença de insetos vetores da queima-do-broto.

A incorporação de fatores de resistência a pragas e doenças assegura à cultivar IAC-24 maior homeostase, outro conceito de estabilidade, por apresentar menor variância entre ambientes ( BECKER, 1981).

Os valores de rendimento de grãos $\left(\mathrm{kg} \cdot \mathrm{ha}^{-1}\right)$, da sua variância e do coeficiente de variação das médias, exceto os dados observados em Tarumã, afetados por excessivo acamamento das plantas, suportam a hipótese de que a cultivar IAC-24 apresenta maior homeostase que o IAC- 15 . O conjunto de características morfológicas e fisiológicas encontram-se quadro 6.

Quadro 2. Análise da variância conjunta dos 14 experimentos de soja desenvolvidos em seis municípios do Estado de São Paulo e um de Minas Gerais, em 1994/95,1995/96 e 1996/97

\begin{tabular}{|c|c|c|c|c|c|}
\hline Causas de variação & GL & SQ & $\mathrm{QM}$ & $\mathrm{F}$ & Prob $>F$ \\
\hline Local(L) & 13 & 184082689 & 14160207 & 25,10 & 0,00001 \\
\hline Genótipo(G) & 11 & 12938143 & 6176195 & 2,08 & 0,02476 \\
\hline Interação(GxL) & 143 & 80689832 & 564264 & 2,61 & 0,00001 \\
\hline Blocos (B)/locais & 42 & 16994507 & 404631 & 1,88 & 0,12945 \\
\hline B/C. das Alagoas(1) & 3 & 344726 & 114909 & 0,53 & 0,66497 \\
\hline B/Campinas(1) & 3 & 1557772 & 519257 & 2,40 & 0,06559 \\
\hline B/Mococa $(1)$ & 3 & 432760 & 144253 & 0,67 & 0,57580 \\
\hline B/Tarumã(2) & 3 & 742047 & 247349 & 1,15 & 0,33028 \\
\hline B/Votuporanga(2) & 3 & 4360687 & 1453562 & 6,73 & 0,00038 \\
\hline B/Campinas(2) & 3 & 96927 & 32309 & 0,15 & 0,92932 \\
\hline B/C. das Alagoas(2) & 3 & 250493 & 83498 & 0,39 & 0,76617 \\
\hline B/Tarumã(3) & 3 & 389408 & 129803 & 0,60 & 0,61885 \\
\hline B/Votuporanga(3) & 3 & 3968330 & 1322776 & 6,12 & 0,00070 \\
\hline B/C. das Alagoas(3) & 3 & 365560 & 121853 & 0,56 & 0,64327 \\
\hline B/Mococa $(3)$ & 3 & 1017158 & 339053 & 1,57 & 0,19441 \\
\hline B/Capão Bonito(3) & 3 & 2353789 & 784596 & 3,82 & 0,01023 \\
\hline B/Ribeirão Preto(3) & 3 & 170973 & 56991 & 0,26 & 0,85266 \\
\hline B/Campinas(3) & 3 & 943875 & 314625 & 1,46 & 0,22430 \\
\hline Resíduo & 462 & 118253785 & 255960 & & \\
\hline Total & 671 & 429953461 & & & \\
\hline
\end{tabular}

( $\left.{ }^{1}\right)$ 1994/95. $\left({ }^{2}\right) 1995 / 96 .\left({ }^{3}\right)$ 1996/97. 
Quadro 3. Rendimento de grãos e índice relativo ao padrão IAC-15 de 12 genótipos de soja por locais em experimentos desenvolvidos no período de 1994 a 1997

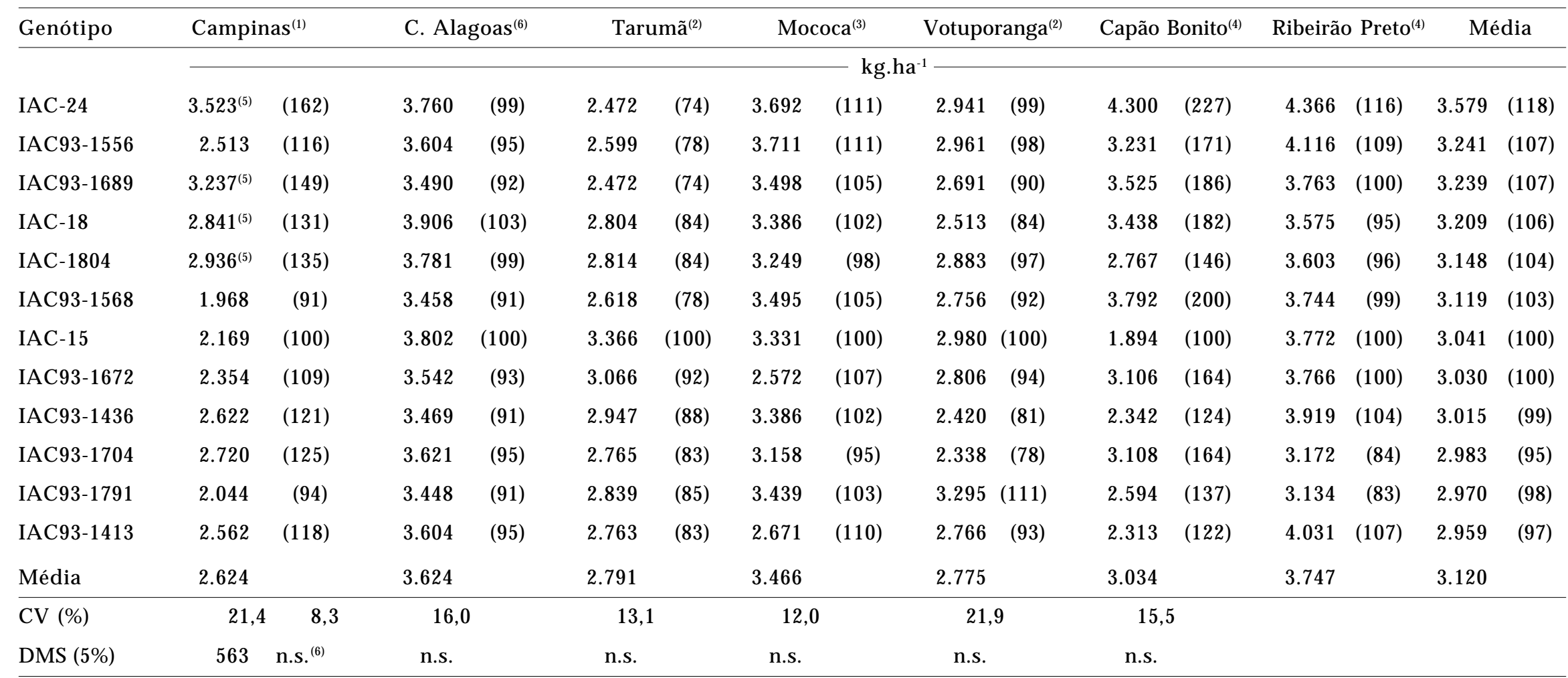

(1) 1994/95, 1995/96 e 1996/97. $\left({ }^{2}\right)$ 1995/96 e 1996/97. $\left(^{3}\right)$ 1994/95 e 1996/97. $\left({ }^{4}\right)$ 1996/97. $\left({ }^{5}\right)$ Difere para mais do padrão IAC-15 ao nivel de 5\%, $\left({ }^{6}\right)$ Efeito não significtivo para genótipos dentro de locais. 
Quadro 4. Análise da variância dentro de locais, Campinas (94/95, 95/96 e 96/97), Conceição das Alagoas (94/95,95/96 e 96/97), Tarumã (95/96 e 96/97), Mococa (94/95 e 96/97 e Votuporanga (95/96 e 96/97)

\begin{tabular}{|c|c|c|c|c|c|}
\hline & $\begin{array}{l}\text { Graus de } \\
\text { Liberdade }\end{array}$ & $\begin{array}{c}\text { Soma de } \\
\text { Quadrados }\end{array}$ & $\begin{array}{c}\text { Quadrado } \\
\text { Médio }\end{array}$ & Valor F & Prob. $>\mathrm{F}$ \\
\hline \multicolumn{6}{|l|}{ Campinas } \\
\hline Ano & 2 & 13401609 & 6700804 & 26,34 & 0,00002 \\
\hline Genótipo & 11 & 28808818 & 2618983 & 10,29 & 0,00002 \\
\hline Interação G x A & 22 & 5597406 & 254427 & 0,80 & 0,70872 \\
\hline Bloco / Ano & 9 & 2598574 & 288730 & 0,92 & 0,56275 \\
\hline Resíduo & 99 & 31141451 & 314560 & & \\
\hline
\end{tabular}

\section{Conceição das Alagoas}

\begin{tabular}{|c|c|c|c|c|c|}
\hline Ano & 2 & 14724830 & 7362415 & 29,51 & 0,00001 \\
\hline Genótipo & 11 & 3154901 & 286809 & 1,15 & 0,37322 \\
\hline Interação G x A & 22 & 5489360 & 249516 & 2,74 & 0,00053 \\
\hline Bloco/Ano & 9 & 960779 & 106753 & 1,17 & 0,32327 \\
\hline Resíduo & 99 & 9000075 & 90910 & & \\
\hline Total & 143 & 33329945 & & & \\
\hline \multicolumn{6}{|l|}{ Tarumã } \\
\hline Ano & 1 & 575361 & 575361 & 2,66 & 0,12821 \\
\hline Genótipo & 11 & 5373990 & 488545 & 2,26 & 0,09590 \\
\hline Interação G x A & 11 & 2376292 & 216027 & 1,09 & 0,38401 \\
\hline Bloco / Ano & 6 & 1131455 & 188576 & 0,95 & 0,57673 \\
\hline Resíduo & 66 & 13096919 & 198438 & & \\
\hline
\end{tabular}

\begin{tabular}{lll}
\hline Total & 95 & 22554017
\end{tabular}

\section{Mococa}

\begin{tabular}{|c|c|c|c|c|c|}
\hline Ano & 1 & 24796501 & 24796501,00 & 51,71 & 0,00008 \\
\hline Genótipo & 11 & 2721899 & 247445,00 & 0,52 & 0,85613 \\
\hline Interação G x A & 11 & 5274274 & 479479,00 & 2,33 & 0,01706 \\
\hline Bloco / Ano & 6 & 1449919 & 241653,00 & 1,17 & 0,32558 \\
\hline Resíduo & 66 & 13565331 & 205535,00 & & \\
\hline Total & 95 & 47807924 & & & \\
\hline \multicolumn{6}{|l|}{ Votuporanga } \\
\hline Ano & 1 & 6215399 & 6215399,00 & 28,69 & 0,00042 \\
\hline Genótipo & 11 & 6121212 & 556474,00 & 2,57 & 0,06648 \\
\hline Interação $\mathrm{G} \times \mathrm{A}$ & 11 & 2383345 & 216668,00 & 1,94 & 0,04942 \\
\hline Bloco / Ano & 6 & 8329017 & 1388169,00 & 12,42 & \\
\hline Resíduo & 66 & 7375427 & 111749,00 & & \\
\hline Total & 95 & 30424400 & & & \\
\hline
\end{tabular}


Quadro 5. Avaliação e seleção de genótipos de soja, tendo como atributos o rendimento de grãos (kg.ha-1 $)$ e a ecovalência expressa em porcentagem da soma de quadrados da interação genótipo ambiente (W\%) e significância em relação aos desvios da regressão

\begin{tabular}{lccccc}
\hline \multirow{2}{*}{ Genótipo } & \multicolumn{2}{c}{ Méritos } & & Critérios $\left(^{*}\right)$ \\
& \multicolumn{1}{c}{ Rendimento de grãos } & Ecovalência & IAC-15 & $\begin{array}{c}\text { significância } \\
\text { dos desvios }\end{array}$ & Seleção(**) \\
\cline { 2 - 3 } IAC-24 & 3.480 & W\% & & & $\mathrm{N}$ \\
IAC93-1689 & 3.199 & 16,76 & 1 & 0 & $\mathrm{~N}$ \\
IAC-18 & 3.190 & 11,14 & 1 & 0 & $\mathrm{~N}$ \\
IAC93-1804 & 3.172 & 6,16 & 1 & 0 & $\mathrm{~S}$ \\
IAC93-1556 & 3.154 & 5,6 & 1 & 1 & $\mathrm{~S}$ \\
IAC93-1672 & 3.103 & 3,89 & 1 & 1 & $\mathrm{~S}$ \\
IAC93-1413 & 3.089 & 3,31 & 1 & 1 & $\mathrm{~N}$ \\
IAC-15 & 3.062 & 4,73 & 1 & 1 & $\mathrm{~N}$ \\
IAC93-1436 & 3.003 & 15,35 & 0 & 0 & $\mathrm{~N}$ \\
IAC93-1704 & 2.988 & 4,28 & 0 & 1 & $\mathrm{~N}$ \\
IAC93-1568 & 2.968 & 4,44 & 0 & 1 & $\mathrm{~N}$ \\
IAC93-1791 & 2.954 & 11,0 & 0 & 0 & 0 \\
\hline Média & 3.114 & 13,34 & 0 & & \\
Soma & 100 & & & & \\
\hline
\end{tabular}

$\left({ }^{*}\right) 1=$ rendimento superior ao do cultivar IAC-15 e com desvios não significativos; $0=$ rendimento inferior ao do cultivar IAC-15 e com desvios significativos; ${ }^{* *}$ S $\mathrm{S}=$ Selecionado $\mathrm{N}=$ Refugado.

Quadro 6. Descritores morfológicos e fisiológicos do cultivar de soja IAC-24

\section{MORFOLÓGICOS}

1. Cor do hipocótilo:

2. Cor da pubescência:

3. Cor da flor:

4. Cor da vagem(sem pubescência):

5. Cor da vagem(com pubescência):

6. Cor do tegumento da semente:

7. Cor do hilo:

\section{FISIOLÓGICOS}

8. Duração da emergência ao florescimento:

9. Duração da emergência à maturação:

10. Estatura das plantas na maturação:

11. Massa de 100 sementes:

12. Reação à "pústula bacteriana" (Xanthomonas campestris pv. glycines):

13. Reação ao "fogo selvagem" (Pseudomonas seringae pv. tabaci):

14. Reação ao "cancro da haste" (Diaporthe phaseolorum f.sp. meridionalis):

15. Reação ao "mosaico comum" (VMCS):

16. Reação a nematóides de galha (Meloidogyne sp.):

17. Teor de óleo $(\%){ }^{(1)}$ :

18. Teor de proteína $(\%)^{(2)}$ : verde

marrom

branca

marrom-clara

marrom

amarela

marrom

57 dias

124 dias

$72 \mathrm{~cm}$

$13 \mathrm{~g}$

resistente

resistente

resistente

resistente

tolerante

7,9

38,7

$\left({ }^{1}\right)$ Extrator tipo Butt; $\left({ }^{2}\right)$ Método Kjeldahl. 


\section{CONCLUSÃO}

1. As características apresentadas pela cultivar IAC-24, quanto ao desempenho agronômico, associadas à performance de resistência a insetos nocivos à soja, recomendam sua indicação a condições edafoclimáticas similares às dos experimentos, com a adequação populacional nos ambientes de maior crescimento vegetativo.

\section{REFERÊNCIAS BIBLIOGRÁFICAS}

BECKER, H.C. Correlations among some statistical measures of phenotypic stabiltiy. Euphytica, Dordrecht, v.30, p.835-840, 1981.

EBERHART, S.; RUSSELL, S. Stability parameters for comparing varieties. Crop Science, Madison, v.6, p.36-40, 1966.

KANG, M. S.; MILLER, J.D. Genotypes x environment interaction for cane and sugar yield and their implications in sugarcane breeding. Crop Science, Madison, v.24, p. 435-440, 1984.

LAMBERT. L. ; KILLEN, T.C. Multiple insect resistance in several soybean genotypes. Crop Science, Madison, v.24, p.887890, 1984.

LOURENÇÃO, A.L.; COSTA, A.S.; MIRANDA, M.A.C. Sources of resistance to Insect pests and virus vectors in the soybean gemplasm tested at Instituto Agronomico, SP, Brasil. In: World Soybean Reserch Conference, 4., 1989, Buenos Aires. Anais... Buenos Aires: Gráfica SRL, 1989. p.1578-1581.

LOURENÇÃO, A.L.; MIRANDA, M.A.C. Resistência de soja a insetos. I.Comportamento de linhagens e cultivares em relação a Epinotia aporema (Wals.) (Lepidoptera: Tortricidae). Bragantia, Campinas, v.42, p.203-209, 1983.

LOURENÇÃO, A.L.; MIRANDA, M.A.C. Resistência de soja a insetos: VIII. IAC78-2318, linhagem com resistência múltipla. Bragantia, Campinas, v.46, n.1, p.65-72, 1987a.

LOURENÇÃO, A. L.; MIRANDA, M.A.C.; NAGAI, V. Resistência de soja a insetos: VII. Avaliação de danos de percevejos em cultivares e linhagens. Bragantia, Campinas, v.46, n.1, p.45$57,1987 \mathrm{~b}$.
LOURENÇÃO, A.L. ; PEREIRA, J.C.V.N.A.; MIRANDA, M.A.C.; AMBROSANO, G.M.B. Avaliação de danos causados por percevejos e por lagartas em genótipos de soja de ciclos precoce e semiprecoce. Pesquisa Agropecuária Brasileira, Brasília, v.35, p.879-886, 2000.

LOURENÇÃO, A.L.; ROSSETTO, C.J.; MIRANDA, M.A.C. Resistência de soja a Insetos: IV. Comportamento de cultivares e linhagens em relação a Hedilepta Indicata (Fabr.). Bragantia, Campinas, v. 44,n.1, p.149-157, 1985.

LOURENÇÃO, A.L.; YUKI, V.A. Oviposição de Bemisia tabaci (Genn.) (Homoptera: Aleyrodidae) em três variedades de soja sem chance de escolha. Bragantia, Campinas, v.41, p.199-202, 1982.

MIRANDA, F.T.S. Interação genótipos x ambientes em linhagens de soja selecionadas para resistência ao nematóide de cisto. 1999. 141f. Dissertação (Mestrado), Escola Superior de Agricultura "Luiz de Queiroz", USP, Piracicaba.

REZENDE, J.A.M. ; MIRANDA, M.A.C.; MASCARENHAS, H.A.A. Comportamento de cultivares de soja em relação à área foliar comida por lagartas das folhas. Bragantia, Campinas, v.39, p.161-165, 1980

REZENDE, J.A.M.; ROSSETTO, C.J.; MIRANDA, M.A.C. Comportamento de populações paternais e $\mathrm{F}_{1}$ de soja em relação a Colaspis sp. e Diabrotica speciosa (Germar, 1824). Bragantia, Campinas, v.39, p. 15-20, 1980

ROSSETTO, C. J.; IGUE, T. ; MIRANDA, M.A.C. DE; LOURENÇÃO, A. L. Resistência de soja a insetos: VI. Comportamento de genótipos em relação a percevejos. Bragantia, Campinas, v.45,n.2, p.323-335, 1986.

VALLE, G.E.; LOURENÇÃO, A.L. Resistência de genótipos de soja a Bemisia tabaci (Genn.) biótipo B ( Hemiptera: Aleyrodidae). Neotropical Entomology, Londrina, v.31, n.1, p.285295, 2002

WRICKE, G. ; WEBER, E.W. Quantitative genetics and selection in plant breeding. Berlin-New York: Walter de Gruyter, 1986. $406 \mathrm{p}$.

YORINORI, J.T. Método do palito-de-dente, uma seleção de genótipos de soja com resistência ao cancro-da-haste. In: REUNIÃO DE PESQUISA DE SOJA DA REGIÃO CENTRAL DO BRASIL, 16, 1994. Dourados, Atas e Resumos... Londrina: Embrapa, 1994. p.130-131. 